\title{
COMPARAÇÃO FENOLÓGICA DE QUATRO CULTIVARES DE MACIEIRA NA REGIÃO DE PALMAS-PR
}

\author{
Jeferson Benedetti Eilert ${ }^{*}$, Clandio Medeiros da Silva ${ }^{2}$, Paulo Mauricio Centenaro Bueno ${ }^{3}$, \\ Iohann Metzger Bauchrowitz ${ }^{4}$ Nei Moreira Queiroz ${ }^{5}$
}

\footnotetext{
${ }^{1}$ Engenheiro Agrônomo. Mestrando no Programa de Pós-graduação em Genética e Melhoramento. Universidade Estadual de Maringá-UEM. Maringá-PR. *E-mail: jeferson-benedetti@ hotmail.com

${ }^{2}$ Engenheiro Agrônomo. Doutor em Agronomia. Pesquisador na Área de Melhoramento e Genética Vegetal. Instituto Agronômico do Paraná-IAPAR. Londrina-PR.

${ }^{3}$ Engenheiro Agrônomo. Doutor em Agronomia (Produção Vegetal). Professor e pesquisador. Instituto Federal do Paraná-IFPR. Palmas-PR.

${ }^{4}$ Engenheiro Agrônomo. Mestrando no Programa de Pós-graduação em Agronomia. Universidade Estadual de Ponta Grossa-UEPG. Ponta Grossa-PR.

${ }^{5}$ Graduando em Agronomia. Instituto Federal do Paraná-IFPR. Palmas-PR.
}

RESUMO: As cultivares IAPAR 75 (Eva), IAPAR 76 (Ana Bela), IAPAR 77 (Carícia) e IPR Julieta são macieiras precoces, característica que permite o cultivo em regiões mais quentes. As frutas podem ser colhidas e comercializadas anteriormente às cultivares Gala e Fuji, agregando valor a esse produto. O presente trabalho teve por finalidade comparar a fenologia de quatro cultivares de maçã, oriundas do programa de melhoramento do IAPAR, que se encontram no banco de germoplasma da Estação Experimental de Palmas-PR. As avaliações fenológicas das macieiras foram semanais, segundo descrição de Fleckinger (1953), nos anos de 2014 e 2015. A macieira é dependente de baixas temperaturas para quebra de dormência natural, e a exigência dessas cultivares variam de 100 a 450 unidades de frio para superação dessa dormência. Na região de Palmas, que possui invernos rigorosos, essas cultivares se mostram precoces e isso é um fator limitante para a produção, que se torna de risco, comprovando-se com a ocorrência de fortes geadas tardias durante a avaliação de 2015. Dessa forma, essas cultivares devem ser recomendadas para outras regiões, onde a ocorrência de geadas tardias é menor.

Palavras-chave: Malus domestica. Germoplasma. Fenologia.

\section{PHENOLOGICAL COMPARISON OF FOUR APPLE CULTIVARS IN PALMAS- PR}

\begin{abstract}
IAPAR 75 (Eva), IAPAR 76 (Ana Bela), IAPAR 77 (Carícia) and IPR Julieta are early apple cultivars, a feature that allows its production in warmer regions. These fruits can be harvested and marketed before Gala and Fuji's fruits, adding value to the product. This study aimed to compare the phenology of four apple cultivars coming from IAPAR breeding program, which are in the germplasm bank of Palmas' Experimental Station. The evaluations of the apple trees' phenology were carried out weekly, according to Fleckinger's (1953) description, in 2014 and 2015. The apple tree is a low-temperature dependent to its natural
\end{abstract}

Cultura Agronômica, Ilha Solteira, v.26, n.3, p.320-329, 2017 
break dormancy, and these cultivars' requirements vary from 100 to 450 cold units for overcoming its dormancy. In the region of Palmas, which has cold winters, these cultivars are very early, and it is a limiting factor for the production that becomes risk, confirming the occurrence of a powerful late frost occurred during the 2015 evaluation. Thus, we recommend that these apple cultivars utilize other regions where the probability of late frosts occur less often.

Key words: Malus domestica. Germplasm. Phenology.

\section{INTRODUÇÃO}

Na década de 1980, através do programa de melhoramento genético do IAPAR foram lançadas as cultivares IAPAR 75 (Eva), IAPAR 76 (Ana Bela), IAPAR 77 (Carícia) e IPR Julieta. (PETRI et.al., 2011). Todas cultivares com baixa exigência em frio, desenvolvidas na estação experimental de Palmas, município esse que possui características favoráveis para o cultivo da macieira, a qual é exigente em baixas temperaturas para a quebra de sua dormência (PETRI et al., 2006).

A cultivar IAPAR 75 - (Eva) é resultante do cruzamento entre Anna e Gala, em 1979. Esta cultivar exige de 100 a 450 unidades de frio para a superação de sua dormência hibernal. Apresenta produtividade alta (superior a 30 ton./ha). Apresenta tolerância à mancha foliar de glomerella (Colletotrichum spp.) e susceptibilidade à sarna da macieira (Venturiaina equalis). Seu cultivo é recomendado onde o acúmulo médio de unidades de frio está entre 50 e 550 (IAPAR, 2010).

IPR Julieta é resultado do cruzamento entre Anna e Mollie's Delicious, no ano de 1979. É muito utilizada como polinizadora da cultivar Eva, por ser igualmente precoce e produz frutos grandes atrativos e saborosos. A fenologia se aproxima da Mollie's Delicious, com vigor moderado/alto, ramos abertos, internódios e folhas grandes. Recomendada para regiões onde o acumulo médio de unidades de frio oscila entre 50 e 550 (IAPAR, 2009).

A macieira IAPAR 76 (Ana Bela) oriunda do cruzamento entre Anna e Gala, em 1979, apresentando baixa exigência em frio, boa produtividade, precocidade e adapta- se bem no centro sul do Paraná. É recomendada para regiões onde ocorrem entre 100 e 250 horas abaixo de $7,2^{\circ} \mathrm{C}$ (IAPAR, 1995).

A cultivar IAPAR 77 (Carícia) é o cruzamento entre Anna e Prima, em 1979. Tem como principais características a precocidade, a baixa exigência em frio, alta produtividade, frutos de boa qualidade e boa adaptação no centro-sul do Paraná. É recomendada para regiões do estado onde acorrem entre 200 e 450 horas abaixo de $7^{\circ} \mathrm{C}$ (IAPAR, 1998).

O presente trabalho teve por finalidade comparar a fenologia das quatro cultivares de maçã oriundas do programa de melhoramento de maçã do IAPAR presentes no banco de germoplasma da Estação Experimental de Palmas-PR.

Cultura Agronômica, Ilha Solteira, v.26, n.3, p.320-329, 2017 


\section{MATERIAL E MÉTODOS}

O estudo foi realizado na Estação Experimental de Palmas - PR do Instituto

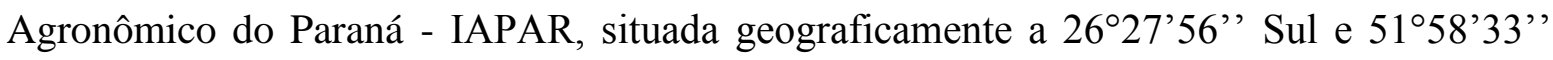
Oeste, com altitude aproximada de 1088 metros.

O município de Palmas possui altitudes que variam de 950 a $1.400 \mathrm{~m}$ e clima $\mathrm{Cfb}$, segundo a classificação de Köppen, com invernos bastante frios, verões frescos e não possui estação seca definida. $\mathrm{O}$ mês mais quente é janeiro e a média de temperatura é de $20,3^{\circ} \mathrm{C}$, o mês mais frio é julho com uma temperatura média de $11,7^{\circ} \mathrm{C}$. A precipitação média é de 2.110 mm por ano (IAPAR, 2013).

Foram utilizados como porta-enxertos os genótipos Marubakaido (MARUBA) e o inter enxerto de EM-9, espaçadas dois metros entre plantas e quatro metros entre linhas.

Cada cultivar possui quatro plantas, sendo que cada planta compôs uma parcela experimental, portanto, o trabalho foi realizado com quatro repetições. $\mathrm{O}$ banco de germoplasma foi implantado no ano de 2012.

As macieiras foram conduzidas sob o sistema líder central, que é um sistema de condução onde a planta é mantida com um ramo principal de crescimento vertical, e dele partem diversos ramos laterais, onde serão obtidos os frutos (SCARPARI FILHO et al., 2011).

Foram dois anos de avaliações semanais da fenologia das macieiras, realizado nas quartas-feiras pela manhã e durante todo o período foi seguido o mesmo critério. Essas avaliações tiveram por base uma tabela desenvolvida por Fleckinger (1953).

No primeiro ano, as avaliações tiveram início no dia 23 de julho de 2014, e terminaram no dia 7 de janeiro de 2015, e neste período foram acumuladas 251 unidades de frio (IAPAR, 2016). No segundo ano, as avaliações tiveram início no dia 22 de julho de 2015 e terminaram no dia 25 de novembro de 2015, com um total de 265,5 unidades de frio acumuladas. (IAPAR, 2016).

As macieiras eram avaliadas de posse de uma prancheta, com um mapa e croqui do experimento, onde continham espaços para anotação com caneta esferográfica. As avaliações foram realizadas observando-se as estruturas reprodutivas e realizando-se uma média, atribuindo letras para cada planta, tendo como base a tabela comparativa, baseada na escala de Fleckinger (1953), como pode ser observado na Figura 1. 


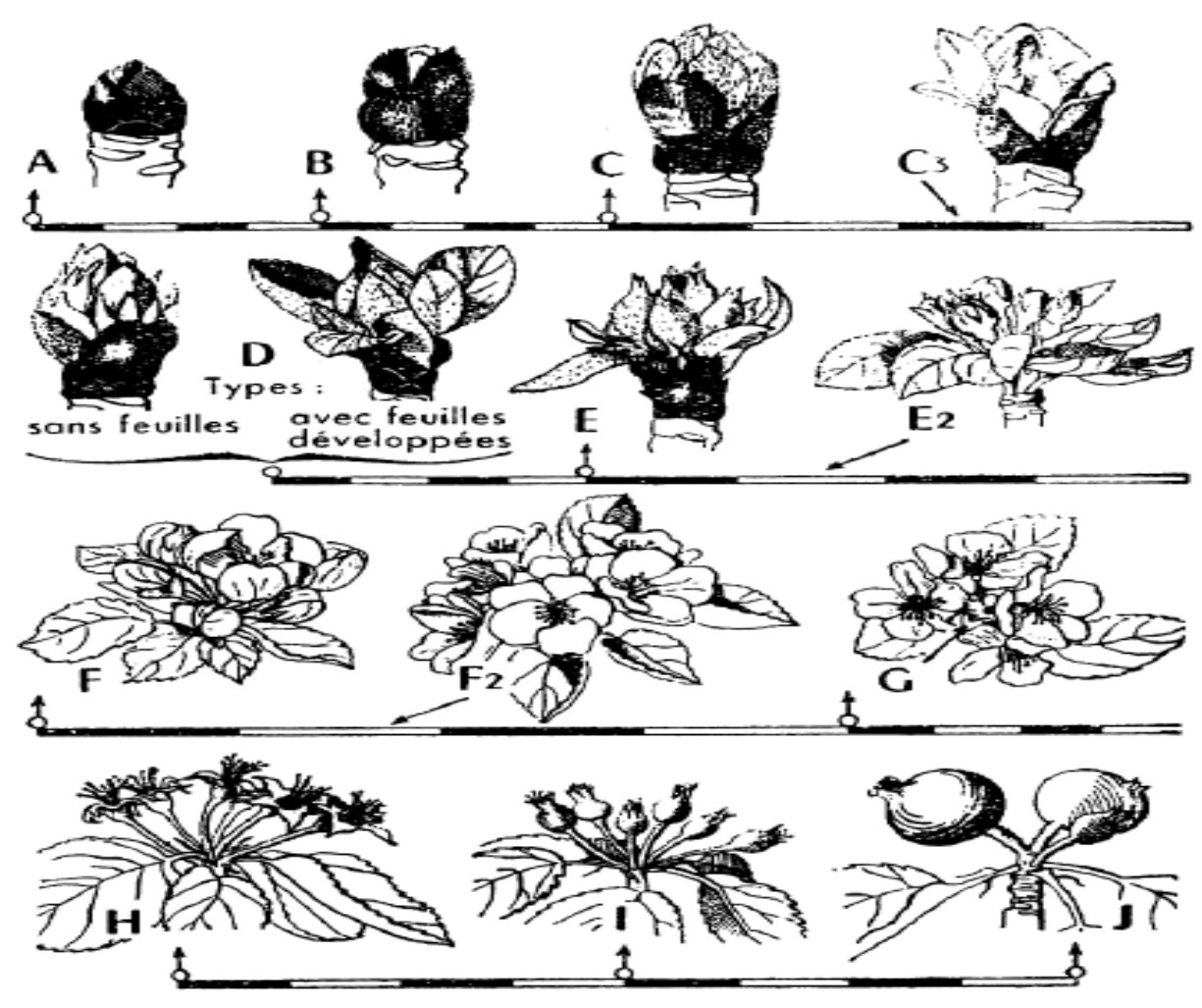

Figura 1. Estádios fenológicos da macieira, segundo Fleckinger (1953). (A): gema dormente, (B) gema inchada com ponta de prata, (C) pontas verdes, (C3) meia polegada verde, (D) meia polegada verde sem folhas, (D2) meia polegada verde com folhas, (E) botão verde, (E2) botão rosado, (F) início da floração, (F2) plena floração, (G) final da floração, (H) queda de pétalas, (I) frutificação efetiva, (J) frutos verdes.

Fonte: Travers (2004).

No fim do período de avaliação, quando todas as plantas já se encontravam no estádio final $(\mathrm{J})$ os dados foram compilados, e repassados para uma tabela virtual no programa excel, onde foram calculadas as médias para as 4 cultivares.

A forma como esses dados foram processados seguiu a seguinte metodologia: as letras correspondentes a cada estádio fenológico foram substituídas por números, respectivamente: (A-1, B-2, C-3, C3-4, D-5, D2-6, E-7, E2-8, F-9, F2-10, G-11, H-12, I-13, J-14), e foram estabelecidas as médias das quatro plantas. Posteriormente esses valores numéricos foram novamente transformados em letras usando-se o mesmo critério acima citado.

\section{RESULTADOS E DISCUSSÃO}

Muitos fatores influenciam o processo produtivo da macieira, e dentre eles o fator climático é de grande importância. Segundo Cardoso (2011), a fenologia da macieira é influenciada fortemente por fatores climáticos e para que se inicie um novo ciclo vegetativo, com brotação e floração adequada, as baixas temperaturas contínuas no inverno são

Cultura Agronômica, Ilha Solteira, v.26, n.3, p.320-329, 2017 
indispensáveis, assim como as condições térmicas na primavera e verão possuem influenciua direta no desenvolvimento dessa planta. Com base nisso, foram elaborados gráficos para os anos de avaliações que contém dados de temperatura máxima, temperatura média, temperatura mínima e precipitação, que podem ser observados na Figura 2.
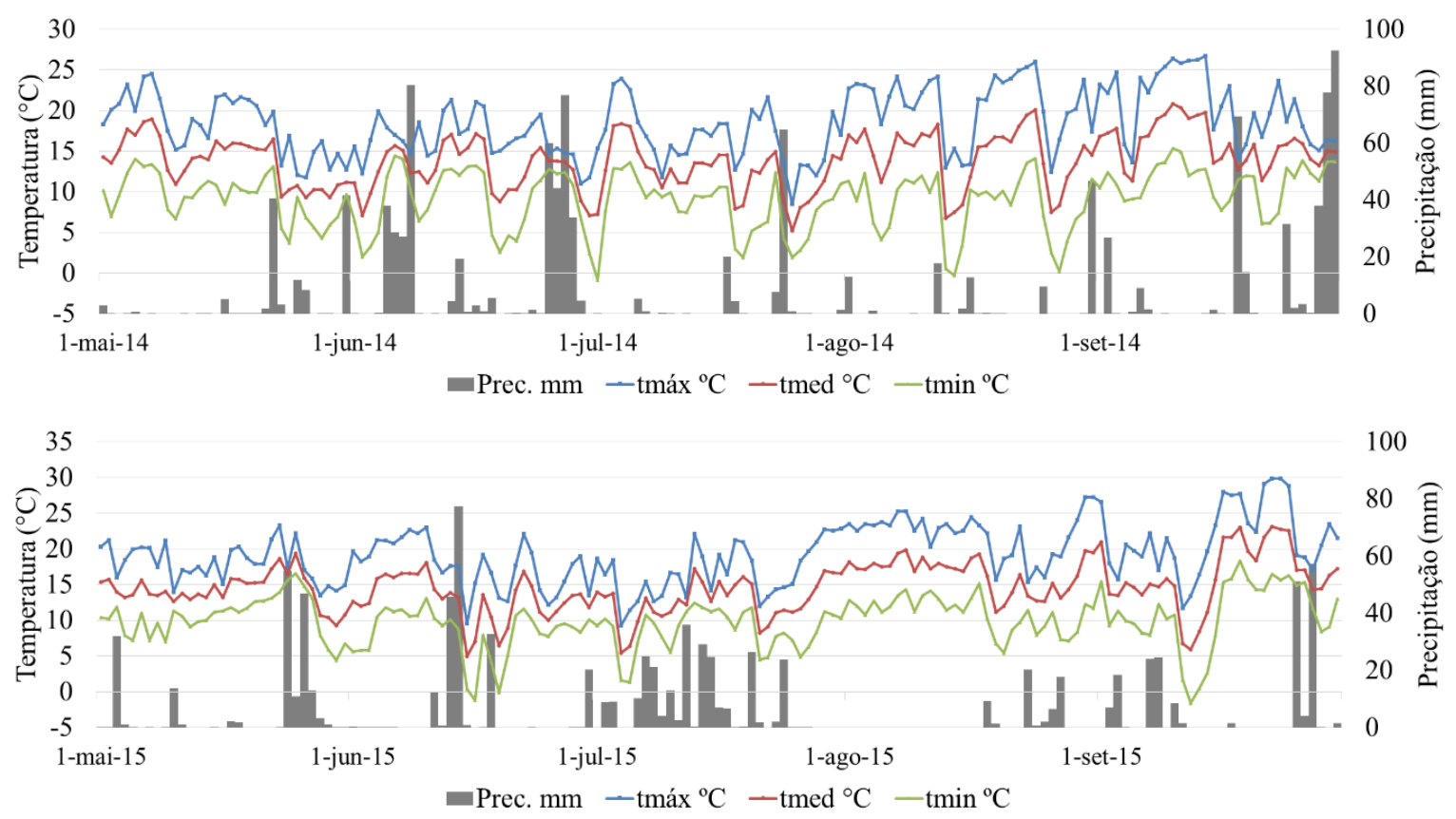

Figura 2. Dados de temperaturas máxima, media, mínima $\left({ }^{\circ} \mathrm{C}\right)$ e precipitação $(\mathrm{mm})$ no período de maio a setembro dos anos de 2014 e 2015.

Fonte: IAPAR (2016).

As quatro cultivares apresentam baixa exigência em frio, sendo classificadas como cultivares precoces. Nas condições climáticas de Palmas esse comportamento não é interessante, uma vez que no município existe uma alta probabilidade da ocorrência de geadas tardias. Geada após a brotação das macieiras pode causar o abortamento de flores, e consequentemente, uma menor frutificação efetiva (HOFFMANN; NACHTIGALL, 2004).

Na Figura 3 é possível observar o histórico da ocorrência de geadas nos últimos dez anos no Estado do Paraná. Boa parte das macieiras de baixo requerimento em frio apresentam brotações no mês de agosto na região de Palmas, porém existem relatos de ocorrência de geadas até o mês de setembro.

Cultivares precoces são desejadas em regiões com temperaturas mais elevadas, onde não existe a ocorrência de geadas tardias, e o limitante de produção é justamente a falta de unidades de frio necessárias para a quebra de dormência dessas macieiras. Essa baixa exigência em frio é importante para regiões com invernos mais amenos, que são desprovidos de temperaturas hibernais frias, a exemplo de São Paulo, Minas Gerais e algumas regiões mais quentes do Paraná (CHAGAS et al., 2006).

Cultura Agronômica, Ilha Solteira, v.26, n.3, p.320-329, 2017 


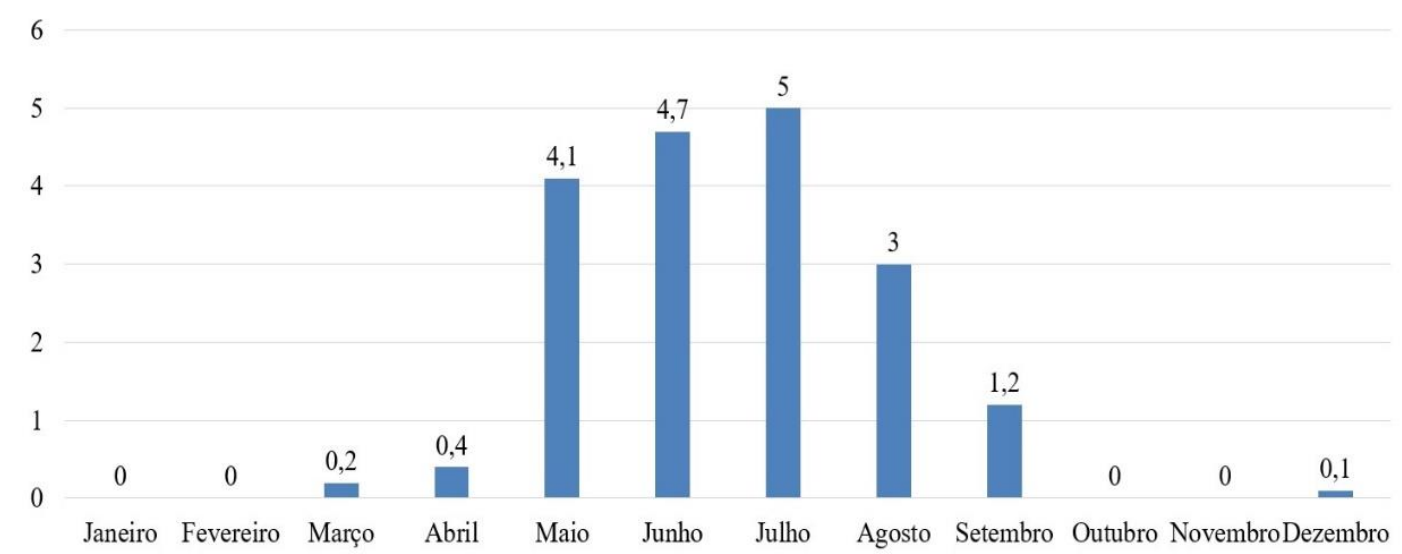

Figura 3. Incidência mensal de geadas no estado do Paraná a partir do ano 2005 até 2015. Fonte: IAPAR (2016).

Outra vantagem dessas cultivares para essas regiões é a possibilidade de comercializar as frutas antes do início da colheita das cultivares Gala e Fuji, aproveitando os preços mais elevados. As macieiras Fuji e Gala necessitam de 1000 a 1100 unidades de frio para quebra de dormência natural, sem atingir essa exigência de frio, a macieira não será produtiva, ou não expressará seu potencial máximo, produzindo menos e frutos de menor valor comercial (SOLTÉSZ, 2003).

Esse problema é praticamente nulo com as macieiras desenvolvidas pelo programa de melhoramento do IAPAR, em especial a macieira Eva, que segundo o pesquisador responsável pelo lançamento da cultivar (HAUAGGE, 2007), essa macieira é menos exigente em baixas temperaturas.

Através do trabalho constatou-se que a quantidade de frio que ocorreu na região do pomar foi suficiente para quebra de dormência natural em ambos os anos, sendo que em 2014 foram registradas 251 unidades de frio e no ano de 2015 os registros são de 256,5 unidades de frio, na localidade onde se encontra o banco de germoplasma, e a exigência da cultura varia de 100 a 450 unidades de frio (HAUAGGE, 2007).

Dentre as quatro cultivares, a que saiu antes da dormência no ano de 2014 foi a cultivar Ana Bela, pois já se encontrava no estádio meia polegada verde sem folhas (D) no momento da primeira avaliação (27/07/2014), seguida pelas cultivares Carícia e Julieta que nessa mesma data estavam no estádio de pontas verdes (C) e a macieira Eva que estava no estádio de gema inchada, ponta de prata (B). A dormência é um fenômeno biológico, ocorre em frutíferas de clima temperado. Passar pelo período de dormência é necessário para essas plantas, e as baixas temperaturas possuem a função de iniciar e terminar a dormência (PETRI et al., 2006).

O início da floração é caracterizado pelo estádio (F) e a primeira macieira que iniciou a floração foi a Carícia, entre os dias 06 e 13/08/2014, nessa data ainda é muito comum a ocorrência de geadas no município de Palmas. A cultivar Eva iniciou a floração entre os dias 03 e 10/09/2014. A macieira Ana Bela entrou no estágio de início da florada entre os dias 27/08/2014 e 03/09/2014. A cultivar Julieta iniciou sua florada no dia 27/08/2014. Esse Cultura Agronômica, Ilha Solteira, v.26, n.3, p.320-329, 2017 
estádio de início da florada é um momento importante para o melhoramento dessa frutífera, quando grande parte das estruturas florais se encontram em balão rosado, que é o estádio citado por Albuquerque Junior et al. (2010), em estudo com cruzamentos em macieiras.

O período em que ocorre a fecundação das flores para posteriormente a planta formar o fruto é entre os estádios (F) início da floração e (G) final da floração. As cultivares Eva, Ana Bela e Julieta possuem períodos de floração coincidentes, dessa uma pode ser a polinizadora da outra. A cultivar Carícia apresentou nesse ano uma florada mais precoce que as demais e não pôde ser polinizada e nem polinizar as demais macieiras. A macieira é uma cultura que depende de polinização cruzada, e exige a presença de plantas geneticamente compatíveis para que seja sua polinizadora, assegurando assim uma boa frutificação (DENARDI; STUKER, 2008).

As primeiras macieiras a atingirem o último estádio da avaliação, o estádio de frutos verdes (J), foram as cultivares Carícia e Ana Bela no dia 17/09, seguida pelas cultivares Eva e Julieta que apresentaram frutos no dia 24/09. Nesse estádio é realizado uma prática importante no pomar, o raleio dos frutos, que consiste em remover o excesso de frutos da planta, evitando assim a alternância de produção e melhorando a qualidade desses frutos. (CAMILO; PEREIRA, 2006). Os dados da fenologia podem ser observados na Figura 4.

\begin{tabular}{|c|c|c|c|c|c|c|c|c|c|c|c|c|c|c|c|}
\hline \multirow{3}{*}{ CULTIVAR } & \multicolumn{15}{|c|}{2014} \\
\hline & \multicolumn{2}{|c|}{ JULHO } & \multicolumn{4}{|c|}{ AgOSTO } & \multicolumn{4}{|c|}{ SETEMBRO } & \multicolumn{5}{|c|}{ OUTUBRO } \\
\hline & 23 & 30 & 6 & 13 & 20 & 27 & 3 & 10 & 17 & 24 & 1 & 8 & 15 & 23 & 29 \\
\hline \multirow{4}{*}{$\begin{array}{l}\text { EVA } \\
\text { CARÍCIA } \\
\text { ANA BELA } \\
\text { JULIETA }\end{array}$} & B & B & $\mathrm{C}$ & D & D & D2 & E & F2 & I & $\mathrm{J}$ & $\mathrm{J}$ & $\mathrm{J}$ & $\mathrm{J}$ & $\mathrm{J}$ & $\mathrm{J}$ \\
\hline & $\mathrm{C}$ & D & E2 & $\mathrm{F} 2$ & G & $\mathrm{H}$ & $\mathrm{H}$ & I & $\mathrm{J}$ & $\mathrm{J}$ & $\mathrm{J}$ & $\mathrm{J}$ & $\mathrm{J}$ & $\mathrm{J}$ & $\mathrm{J}$ \\
\hline & D2 & $\mathrm{E}$ & E2 & $\mathrm{F}$ & F2 & $\mathrm{H}$ & $\mathrm{H}$ & I & $\mathrm{J}$ & $\mathrm{J}$ & $\mathrm{J}$ & $\mathrm{J}$ & $\mathrm{J}$ & $\mathrm{J}$ & $\mathrm{J}$ \\
\hline & $\mathrm{C}$ & $\mathrm{C}$ & $\mathrm{C}$ & D2 & E & $\mathrm{F}$ & $\mathrm{F} 2$ & G & $\mathrm{H}$ & $\mathrm{J}$ & $\mathrm{J}$ & J & $\mathrm{J}$ & $\mathrm{J}$ & $\mathrm{J}$ \\
\hline & \multicolumn{15}{|c|}{2015} \\
\hline \multirow{2}{*}{ CULTIVAR } & \multicolumn{2}{|c|}{ JULHO } & \multicolumn{4}{|c|}{ AGOSTO } & \multicolumn{5}{|c|}{ SETEMBRO } & \multicolumn{4}{|c|}{ OUTUBRO } \\
\hline & 22 & 29 & 5 & 12 & 19 & 26 & 2 & 9 & 16 & 23 & 30 & 7 & 14 & 21 & 28 \\
\hline EVA & B & $\mathrm{C}$ & $\mathrm{C} 3$ & E2 & F2 & $\mathrm{H}$ & I & $\mathrm{J}$ & $\mathrm{J}$ & $\mathrm{J}$ & $\mathrm{J}$ & $\mathrm{J}$ & $\mathrm{J}$ & $\mathrm{J}$ & $\mathrm{J}$ \\
\hline CARÍCIA & B & B & $\mathrm{C} 3$ & E & $\mathrm{F} 2$ & $\mathrm{H}$ & I & $\mathrm{J}$ & $\mathrm{J}$ & $\mathrm{J}$ & $\mathrm{J}$ & $\mathrm{J}$ & $\mathrm{J}$ & $\mathrm{J}$ & $\mathrm{J}$ \\
\hline ANA BELA & B & C & $\mathrm{C} 3$ & E2 & F2 & $\mathrm{H}$ & I & $\mathrm{J}$ & $\mathrm{J}$ & $\mathrm{J}$ & $\mathrm{J}$ & $\mathrm{J}$ & J & $\mathrm{J}$ & J \\
\hline JULIETA & B & B & C3 & $\mathrm{E}$ & F2 & $\mathrm{H}$ & I & J & J & $\mathrm{J}$ & $\mathrm{J}$ & $\mathrm{J}$ & J & $\mathrm{J}$ & $\mathrm{J}$ \\
\hline
\end{tabular}

LEGENDA: \begin{tabular}{|l|l|l|l|l|l|l|l|l|l|l|l|l|l|} 
A & B & C & C3 & D & D2 & E & E2 & F & F2 & G & H & I & J \\
\hline
\end{tabular}

Figura 4. Avaliação da escala fenológica nos anos de 2014 e 2015 das quatro cultivares de macieira presentes no banco de germoplasma do IAPAR, onde: (A) gema dormente; (B) gema inchada com ponta de prata, (C) pontas verdes, (C3) meia polegada verde, (D) meia polegada verde sem folhas, (D2) meia polegada verde com folhas, (E) botão verde, (E2) botão rosado, (F) início da floração, (F2) plena floração, (G) final da floração, (H) queda de pétalas, (I) frutificação efetiva, (J) frutos verdes.

Nos dias 12 e 13 de setembro de 2015 ocorreram fortes geadas no município de Palmas, afetando as macieiras em seu estádio reprodutivo. Das flores e frutos afetados, grande parte caiu da planta mãe, muito dos frutos que continuaram o ciclo apresentaram uniformidades 
que os torna inviável ao mercado. De acordo com Scheeren et al. (2012), muitas frutas são desqualificadas para a comercialização, pois, apresentam características que fogem aos padrões de qualidade, e muito desse prejuízo é causado por condições climáticas adversas.

Podemos observar na Figura 4, que no ano de 2015 os resultados obtidos para essas macieiras foram mais homogêneos, quando comparados com o ano de 2014, onde se visualiza uma variação maior no início da fase reprodutiva (Figura 4). Segundo Soltész (2003), quando o florescimento ocorre simultaneamente, coincidindo períodos de plena floração entre as plantas no pomar, a frutificação é melhor, ou seja, quanto mais homogênea for a floração melhor será a frutificação e consequentemente a produção.

Na data da primeira avaliação (22/07/2015) todas as quatro cultivares avaliadas já haviam saído da dormência e se encontravam em estado de gema inchada, ponta de prata (B). Entre os dias 12 e 19/08/2015 as macieiras iniciaram a floração (F), sendo que no dia 19/08/2015 estavam todas em estádio de plena florada (F2). As quatro macieiras atingiram o estádio de frutos verdes, o último estádio da escala fenológica no dia 09/09/2015. A avaliação fenológica não se estendeu até a maturação dos frutos, porém Santos et al. (2011), citam que o período de acúmulo de matéria seca, desde o início da formação do fruto até a maturação fisiológica dos mesmos foram de 86 dias para a cultivar Eva, produzida no submédio São Francisco.

A diferença no início da fase reprodutiva entre as quatro cultivares nos diferentes anos de avaliação pode ser explicado, através de uma observação da Figura 2, onde as variações climáticas no ano de 2014 são mais intensas possuindo picos maiores de temperaturas altas e temperaturas baixas, e também com relação à quantidade de unidades de frio acumulada, sendo que no ano de 2015 essa quantidade foi maior. O autor Iuchi et al. (2002) cita que podem ocorrer alterações e anomalias nas macieiras, quando ocorrem constantes mudanças climáticas. Segundo Petri (2006), quando a quantidade de frio exigido pela cultura não é atingido as gemas vegetativas e floríferas permanecem dormentes, mesmo quando as condições ambientais são favoráveis para o crescimento.

\section{CONCLUSÃO}

Para a região de Palmas, que possui invernos rigorosos, essas cultivares se mostram muito precoces e isso é um fator limitante para a produção, que se torna de risco, devido à ocorrência de temperaturas negativas e geadas após o início da brotação e florescimento das plantas.

Dessa forma, essas cultivares de macieiras são recomendadas para regiões mais quentes, onde o risco com as geadas tardias é menor.

A partir dos dados obtidos será possível direcionar as novas hibridações para o lançamento de cultivares com características agronômicas interessantes para as diferentes regiões climáticas do Estado do Paraná.

Cultura Agronômica, Ilha Solteira, v.26, n.3, p.320-329, 2017 


\section{AGRADECIMENTOS}

Os autores agradecem ao $\mathrm{CNPq}$ pelo suporte financeiro através de bolsa de pesquisa fornecida ao primeiro autor.

\section{REFERÊNCIAS BIBLIOGRÁFICAS}

ALBUQUERQUE JUNIOR, C. L; DENARDI, F.; DANTAS, A. C. M.; NODARI, R. O. Desenvolvimento de tubos polínicos em cruzamentos entre cultivares brasileiras de macieira. Pesquisa agropecuária brasileira, Brasília, v. 45, n. 11, p.1324-1327, 2010.

CAMILO, A. P.; PEREIRA, A. J. Raleio de frutos. In: EPAGRI. A cultura da macieira. Florianópolis: Epagri, 2006. cap. 14, p. 419-463.

CARDOSO, L. S. Modelagem aplicada a fenologia de macieiras 'Royal Gala' e 'Fuji Suprema' em função do clima, na região de Vacaria, RS. 01/07/2011. 91 f. Tese (Doutorado em Fitotecnia) - Faculdade de Agronomia, Universidade Federal do Rio Grande do Sul, Porto Alegre, 2011.

CHAGAS, E. A.; PIO, R.; CAMPO DALL'ORTO, F. A.; BARBOSA, W. Desenvolvimento de novas cultivares de pêssego para a expansão da cultura em regiões quentes do estado de São Paulo. O Agronômico, Campinas, v. 58, n. 1/2, p. 34-36, 2006.

DENARDI, F.; STUKER, H. Eficiência de diferentes cultivares de macieira como polinizadoras da 'Castel Gala' e da 'Condessa'. Agropecuária Catarinense, Florianópolis, v. 21, n. 1, p.79-83, 2008.

FLECKINGER, J. Observations récents sur 1'écologie du pommier à cidre. In: CONGRÈS INTERNATIONAL DE BOTANIQUE ET D‘AGRONOMIE, 1953, Versailles. Comunication 8... Versailles: INRA, Station d'Amélioration des Plantes, 1953. p. 14.

HAUAGGE, R. Fruticultura: Opção de Desenvolvimento para o Paraná. In: ENCONTRO PARANAENSE DE FRUTICULTURA, 1., 2007, Guarapuava. Anais... Guarapuava: UNICENTRO Universidade Estadual do Centro Oeste, 2007. p. 50-55.

HOFFMANN, A.; NACHTIGALL, G. R. Fatores edafoclimáticos. In: EMBRAPA. Maçã Produção. Brasília: Embrapa, 2004. cap. 4, p. 25-31.

IAPAR. Horas de frio. 2016. Disponível em: http://www.iapar.br/modules/conteudo/conteudo.php?conteudo=2041 Acesso em: 28 fev. 2016.

IAPAR. Médias históricas em estações do IAPAR. 2013. Disponível em: http://www.iapar.br/arquivos/Image/monitoramento/Medias_Historicas/Palmas.htm Acesso em: 19 jun. 2015.

IAPAR. Macieira EVA. Curitiba: Instituto Agronômico do Paraná, 2010. 6 p. (Folheto de divulgação).

Cultura Agronômica, Ilha Solteira, v.26, n.3, p.320-329, 2017 
IAPAR. IPR Julieta. Curitiba: Instituto Agronômico do Paraná, 2009. 6 p. (Folheto de divulgação).

IAPAR. Macieira IAPAR 77 Carícia. Curitiba: Instituto Agronômico do Paraná, 1998. 6 p. (Folheto de divulgação).

IAPAR. Macieira IAPAR 76 Ana Bela. Curitiba: Instituto Agronômico do Paraná, 1995. 6 p. (Folheto de divulgação).

IUCHI, V. L.; IUCHI, T.; BRIGHENTI, E.; DITRICH, R. Quebra da dormência da macieira (Malus domestica Borkh) em São Joaquim. Revista Brasileira de Fruticultura, Jaboticabal, v. 24, n. 1, p.168-174, 2002.

PETRI, L. J.; LEITE, B. G.; COUTO, M.; FRANCESCATTO, P. Avanços na cultura da macieira no brasil. Revista Brasileira de Fruticultura Jaboticabal, v. especial, p. 48-56, 2011 .

PETRI, J. L.; PALlADINI, L. A.; POLA, A. C. Dormência e indução da macieira. In: EPAGRI. A cultura da macieira. Florianópolis: editora: Epagri, 2006. cap. 8, p. 261-298.

SANTOS, A. C. B.; ASSIS, J. S.; SILVA, S. A. B.; LOPES, P. R. C. Crescimento e maturação de maçãs "Eva" e "Princesa" produzidas no submédio São Francisco. In: SIMPÓSIO BRASILEIRO DE PÓS-COLHEITA - SPC, 3., 2011, Nova Friburgo. Anais... São Paulo, editora: Tecart, 2011. p. 740-743.

SCARPARI FILHO, S. A. J.; MEDINA, B. R.; SILVA, R. S. Poda de Árvores Frutíferas. Piracicaba: ESALQ/USP, 2011. 32 p.

SCHEEREN, P.; LEHN, D. N.; SOUZA, C. F. V. Aproveitamento de maçãs não conformes à comercialização na elaboração de pães. Revista destaques acadêmicos, Lajeado, v. 4, n. 4, p.67-75, 2012.

SOLTÉSZ, M. Apple. In: KOZNA, P.; NYÉKI, J.; SOLTÉSZ, M.; SZABO, Z. Floral biology, pollination and fertilisation zone fruit species and grape. Budapest: Akadémia Kiadó, 2003. p. 237-316.

TRAVERS, I. Influence des conditions pédoclimatiques du terroir sur le comportement du pommier et la composition des pommes à cidre dans le Pays d'Auge. 2004. 87 f. Tese (Doutorado em Ciências Agrárias - Biotecnologia agrícola) - Université de Caen Normandie, Caen, 2004. 